\title{
Inhibition of Carrageenan-induced Dental Inflammatory Responses Owing to Decreased TRPV1 Activity by Dexmedetomidine
}

\section{Gang Lu}

Rizhao People's Hospital

\section{Guanhua Zhu}

Jingzhou Central Hospital

Maohua Xu

Rizhao People's Hospital

Xinggao Ping ( $\nabla$ xinggaoping1025@163.com )

Rizhao People's Hospital https://orcid.org/0000-0002-5876-4930

\section{Qingfeng Xiao}

Xiangyang Central Hospital

\section{Research}

Keywords: Dental pulp cell; inflammation; Dex; TRPV1; cytokines

Posted Date: March 20th, 2020

DOI: https://doi.org/10.21203/rs.2.18613/v2

License: (9) This work is licensed under a Creative Commons Attribution 4.0 International License.

Read Full License

Version of Record: A version of this preprint was published at Journal of Inflammation on May 1st, 2020.

See the published version at https://doi.org/10.1186/s12950-020-00245-5. 


\section{Abstract}

Background Dexmedetomidine (Dex) is a highly selective agonist of the a2 adrenergic receptor and a common sedative; however, its anti-inflammatory effect has been studied. In this study, the inhibitory effect of Dex on inflammation in dental pulp cells was assessed. For this, the effect of Dex on inflammation induced by carrageenan (Car) in human dental pulp cells (hDPCs) was evaluated. Car incubation induced a robust inflammatory response in hDPCs as well as activation of PKA-STAT3 and PKC-nuclear factor kappa B (NF-KB) signaling pathways. Results Dex reduced the expression of inflammatory cytokines in a dose-dependent manner. Meanwhile, the phosphorylation of PKA, PKC, STAT3, and NF-KB as well as the nuclear accumulation of STAT3 and NF-KB were significantly increased in Dex-treated Car-induced hDPCs. Western blotting results also showed that the phosphorylation level of transient receptor potential cation channel subfamily V member 1 (TRPV1) was downregulated as a result of Dex treatment. Furthermore, we found that administration of the TRPV1 agonist capsaicin (Cap) reversed the effects of Dex on proinflammatory cytokines; however, the expression and activation of PKA-STAT3 and PKC-NF-KB signals were not altered owing to Cap administration. Conclusions These results indicate that Dex plays a defensive role in dental pulp inflammation by regulating the TRPV1 channel and can be used as a potential target for human dental pulp inflammation intervention.

\section{Introduction}

Pulp exposure and injury leads to pulpitis and induces severe inflammation, frequently resulting in persistent pain and referred pain. Dental pulp inflammation is a common phenomenon, usually a sequela of dental caries or trauma 1. Clinically, it could cause severe pain 2, and if not controlled, it may eventually lead to fatal systemic inflammatory disease 3 . The mechanism of acute pulpitis is complex and involves repetitive trauma, inflammation, bacterial invasion, stimulation of the afferent nerve, secondary hyperalgesia, and in rare cases, periodontitis. Without effective treatment, the outcome is always root canal treatment. Therefore, considering the immediate effects of pulpitis, the identification of a new therapeutic target is significantly important for treating pulpitis. However, several studies have focused on the effect of immune cells 4 , such as macrophages, dendritic cells, and lymphocytes.

Human dental pulp cells (hDPCs) are the main cell types present in dental pulp and play multiple roles in host defense and regeneration 5-7. HDPCs induced by proinflammatory mediators, including tumor necrosis factor alpha (TNF-a) and lipopolysaccharide (LPS), can locally secrete numerous cytokines to attract additional immune cells and initiate and regulate inflammation 8, 9.

During inflammation, primary nociceptive neurons (nociceptors) are sensitized and the pain sensation (hyperalgesia) is increased. The direct effect of inflammatory mediators such as prostaglandins (PGI2 and PGE2) and sympathetic amines (epinephrine and dopamine) on their receptors in the nociceptor membrane can cause sensitization. Transient receptor potential cation channel subfamily $\mathrm{V}$ member 1 (TRPV1), a ligand-gated ion channel, is involved in pain modulation 10. The flavonoid eriodictyol (an 
antagonist of the TRPV1 channel) also plays a part by reducing nociceptive behavior 11. In addition, the nociceptor is partially characterized by the expression of TRPV1 12.

As a specific agonist of the a2 adrenergic receptor, dexmedetomidine (Dex) is commonly used for analgesia and sedation purposes in the operation room and intensive care unit 13,14 . Dex was recently reported to have a protective effect against inflammation that is triggered by endotoxin 15 , spinal cord injury 16 , sepsis 17 , or lung injury 18 . In the present study, carrageenan (Car), an inflammation inducer 19, was used to induce pulp inflammation. STAT3 and NF-KB are common targets for IL-6-induced macrophages and carrageenan-induced mouse paw edema 20, while TRPV1 is crucial for proinflammatory STAT3 signaling 21. Therefore, this study sought to study the protective effect of Dex on Car-induced pulp inflammation and determine the role of TRPV1, STAT3, and NF-KB on inflammation of hDPCs.

\section{Results}

\section{Expression of proinflammatory cytokines induced by Car in hDPCs}

To explore hDPC inflammation following Car treatment, the expression of proinflammatory cytokines in hDPCs was assessed. qPCR and ELISA test results revealed that messenger RNA (mRNA) and protein expressions of IL-1 $1 \beta, \mathrm{IL}-6$, and TNF- $\alpha$ in HDPCs after Car treatment were higher than those in the control group $(P<0.01)$ (Figs. 1A and 1B).

\section{Car-induced activation of PKA-STAT3 and PKC-nuclear factor kappa B (NF-KB) in induced hDPCs}

Because the activation of the PKA-STAT3 and PKC-NF-KB pathways is crucial for inducing cytokine expression 22, 23, the expression and phosphorylation of PKA, STAT3, PKC, and NF-KB after Car treatment were evaluated. qPCR results suggest that Car upregulates the mRNA expressions of STAT3 and NF-KB $(P<0.05)$, while the PKA and PKC expressions were not altered (Fig. 2A). Moreover, the WB results indicated that the levels of PKA, STAT3, PKC, and NF-KB phosphorylation were increased following Car treatment (Fig. 2B). Additionally, the nuclear localization of STAT3 and NF-KB was clearly increased as a result of Car incubation (Fig. 2C). Cellular fractionation was also performed to detect the nuclear $(\mathrm{N})$ and cytoplasmic (C) distribution of STAT3 and NF-KB in hDPCs. The results showed that the " $\mathrm{N}$ " fraction of STAT3 and NF-kB in cells with Car treatment was increased, while the "C" fraction was reduced (Fig. 2D). These results suggest that Car treatment induced inflammatory reactions in hDPCs by activating the PKA-STAT3 and PKC-NF-KB pathways.

\section{Dex ameliorated inflammatory responses triggered by Car}

Previous studies have shown that local Dex administration reverses inflammation induced by Car 24, 25, Therefore, ELISA was utilized to detect the production of proinflammatory cytokines under Car stimulation and various concentrations of Dex. IL-1 $\beta$, IL-6, and TNF-a were downregulated in a dosedependent manner at $2 \mathrm{~h}$ after Dex treatment in hDPCs $(\mathrm{P}<0.05)$ (Figs. 3A, 3B, and 3C). 
WB results showed that PKA, STAT3, PKC, and NF-KB phosphorylation was downregulated in hDPCs owing to stimulation using $5 \mu \mathrm{M}$ Dex $(\mathrm{P}<0.05)$ (Fig. 4A). Meanwhile, we found that STAT3 and NF-KB were redistributed in the cytoplasm following Dex treatment (Fig. 4B), suggesting that these two signaling pathways were blocked as a result of Dex treatment in hDPCs.

\section{Dex desensitized TRPV1 channel in Car-treated hDPCs}

Previous studies have suggested that TRPV1 (a substrate of different protein kinases) is activated by multiple inflammatory mediators, such as PKC 26 and PKA 27. Therefore, we attempted to examine the activation of TRPV1 during Car induction and Dex treatment. qPCR results showed that TRPV1 expression did not significantly change following Dex treatment (Fig. 5A); however, its activity, which was indicated by CGRP release, was clearly reduced after Dex treatment (Fig. 5B). Furthermore, WB indicated that TRPV1 phosphorylation was downregulated and confirmed that its expression did not change (Fig. 5C). The data suggested that TRPV1 was desensitized owing to Dex administration.

\section{Effects of the TRPV1 agonist Cap on inflammation in hDPCs}

To further examine the influence of TRPV1 on Dex-ameliorated and Car-induced inflammation in hDPCs, cells were coadministered $5 \mu \mathrm{M}$ of capsaicin (Cap), a TRPV1 agonist. We found that CGRP release was obviously increased after Cap treatment $(\mathrm{P}<0.05)$ (Fig. 6A). In addition, TPRV1 phosphorylation was markedly increased after hDPCs were coadministered with Cap. Meanwhile, the activation of the PKASTAT3 and PKC-NF-KB pathways was not altered, suggesting that TRPV1 was located downstream of these two pathways (Fig. 6B). In addition, the sensitization of TRPV1 resulted in the restoration of proinflammatory cytokine production (Fig. 6C), suggesting that TRPV1 sensitization counteracts the effects of Dex on hDPC inflammation.

\section{Discussion}

Many molecules can be used to induce hDPC inflammation, including LPS, IL-6, IL-8, and TNF-a. More specifically, LPS can penetrate the dental pulp and induce inflammation and plays a key role in pulp infection 28. Proinflammatory cytokines such as IL-6, IL-8, and TNF- $a$ are usually detected in inflamed pulp and are considered key biomarkers and mediators for the diagnosis of pulp inflammation 29-31. In the present study, Car was used to induce the inflammation of hDPCs. A previous study revealed that the Car-induced acute inflammatory response can be examined to elucidate the inflammatory period related to phagocyte infiltration, excessive production of free radicals, and release of inflammatory mediators, e.g., TNF-a, cyclooxygenase-2, and inducible nitric oxide synthase 32. An in vivo model showed that Carinduced acute inflammatory response reached its peak at 2-3 $\mathrm{h}$ after injection, with the inflammation later disappearing within 24-74 $\mathrm{h} 33$. The inflammatory response induced by Car is considered to be a biphasic situation in which multiple mediators induce the generation of inflammation 34 . In this study, the robust generation of proinflammatory cytokines, i.e., IL-1 $\beta$, IL-6, and TNF- $a$, and the phosphorylation and nuclear localization of STAT3 and NF-KB were observed after 100- $\mu \mathrm{M}$ Car treatment for $2 \mathrm{~h}$. These findings indicated the successful induction of dental pulp inflammation by Car. 
Existing evidence has revealed that TRPV1 is involved in the occurrence and development of immunerelated diseases and is a therapeutic target that is easily blocked by small molecules. For instance, TRPV1 is currently considered to be an anticipated molecular target for the clinical evaluation of epilepsy therapy 37. Its antagonists are employed for the treatment of pruritus, inflammation-related pain, tissue damage, ischemia, and other diseases 38,39 , and its agonists have been used in a phase III clinical trial for the treatment of cluster headache, analgesia, and osteoarthritis 40,41 . Various inflammatory mediators can sensitize TRPV1, including neurotransmitters, cytokines and chemokines, lipids, peptides or small proteins, and growth factors. Many inflammatory mediators enhance the activity of TRPV1 42. TRPV1 is lowly expressed in pulpal sensory neurons relative to their expression in the pulpal trigeminal ganglia 43. LPS treatment in dental trigeminal ganglia induced pulpitis by upregulating expression of the TRPV1 channel 44. Previous studies have shown that local Dex administration reverses inflammation induced by Car $[22,23]$. In the present study, treatment using Dex led to impaired inflammation and deactivation of the TRPV1 channel. Further usage of the TRPV1 agonist Cap restored the generation of proinflammatory cytokines, suggesting that the TRPV1 channel was involved in the Car-triggered inflammation of DPCs.

Previous studies demonstrated that TRPV1 can be activated by inflammatory mediators and corresponding receptors, i.e., PKC 26 and PKA 27. Both kinases can phosphorylate TRPV1 at different serine and threonine residues, resulting in TRPV1 sensitization. Alternatively, the calcium signaling pathway can be activated and TRPV1 phosphorylation can be induced by increased intracellular calcium in the TRPV1 channel, leading to downstream activation of STAT3 21 and NF-KB and cytokine production 45. STAT3, a member of the STAT protein family, is an important regulator in tumor cells and plays a critical role in inflammation and tumorigenesis by regulating cell metabolism 35. STAT3 protein exists in an inactive form in the cytoplasm and can be activated by associated kinases and phosphorylated at multiple phosphorylation sites 36 . The most common form of NF-KB is a heterodimer of $\mathrm{p} 50$ and p65/RelA proteins. Similarly, in the deactivated condition, NF-KB is present in an inactive form that is retained in the cytoplasm by the inhibitory protein IKB. Both STAT3 and NF-KB are transcription factors that are involved in immune responses during inflammation 22, 23. Previous studies have demonstrated that STAT3 46, 47 and NF-KB 22, 48-51 can be upregulated and activated in the inflammatory DPCs or dental pulp stem cells. In the present study, PKA-STAT3 and PKC-NF-KB signaling was activated by Car administration, while Dex treatment clearly reduced the phosphorylation and nuclear subcellular location of STAT3 and NF-KB, indicating that STAT3 and NF-KB activation might be attributed to Car-induced inflammation of DPCs. However, both signals were not altered after Cap administration, indicating that TRPV1 activation occurs downstream of these two signals.

\section{Conclusions}

In summary, our study demonstrated the intrinsic mechanism underlying dental pulp inflammation in hDPCs. Car can induce inflammation by sensitization of TRPV1 via the PKA-STAT3 and PKC-NF-KB pathways, which can be ameliorated by Dex. The present study shows that Dex can be used as a potential drug for gingivitis, which can induce anti-inflammatory potency in dental pulp cells. 


\section{Methods}

\section{Ethics}

All experiments were approved by the Ethics Committee of Rizhao People's Hospital. All subjects signed informed consent forms.

\section{Separation and culture of hDPCs}

Healthy permanent premolars for orthodontic or impacted third molars were collected from subjects aged 18-26 years. As mentioned above, hDPCs were separated and cultured using a previously described enzymatic method 52 . The dental pulp tissue was separated, cut into small pieces, and digested at $37^{\circ} \mathrm{C}$ for $20 \mathrm{~min}$ with $3 \mathrm{mg} / \mathrm{mL}$ of type I collagenase (Gibco, USA). Next, the chopped pulp tissue was cultured at $37^{\circ} \mathrm{C}$ in Dulbecco's modified Eagle's medium (DMEM) containing $20 \%$ fetal bovine serum, $100 \mathrm{U} / \mathrm{mL}$ of penicillin (Gibco, USA), and $100 \mathrm{mg} / \mathrm{mL}$ of streptomycin with $5 \% \mathrm{CO}_{2}$. The medium was replaced every 3 days. After the cells achieved $80 \%$ confluence, they were separated by trypsin/ethylenediaminetetraacetic acid (Gibco, USA) and sub-cultured at a ratio of 1:2.

\section{Dex incubation}

Dex $(1179333$, Sigma, $350 \mu \mathrm{M})$ was frozen at $-20^{\circ} \mathrm{C}$ and diluted with DMEM/F-12 to a specified concentration if necessary. Before Dex treatment, cells were allowed to reach approximately $70 \%-80 \%$ confluence. The cells were exposed to Dex at various concentrations $(0,0.1,1,5$, or $10 \mu \mathrm{M})$ for $2 \mathrm{~h}$ to determine the optimal concentration. Cells were then divided into the following groups: control group, in which the cells were incubated without Dex treatment in a humidified environment at $37^{\circ} \mathrm{C}$ with $5 \% \mathrm{CO}_{2}$; Car group, in which the cells were incubated with $100 \mu \mathrm{M}$ of Car for $2 \mathrm{~h}$; and Dex/Car group, in which the cells were pretreated with $5 \mu \mathrm{M}$ of Dex and $100 \mu \mathrm{M}$ of Car for $2 \mathrm{~h}$.

\section{Drug administration}

To induce an inflammatory response, cells were incubated with Car (C1013, Sigma, $100 \mu \mathrm{M})$ for $2 \mathrm{~h}$. To promote TRPV1 activity, cells were incubated with capsaicin (Cap, 21750, Sigma, $5 \mu \mathrm{M}$ ) for $2 \mathrm{~h}$. To inhibit PKA activity, cells were treated with H-89 (B1427, Sigma, $10 \mu \mathrm{M})$ for $2 \mathrm{~h}$. To inhibitor PKC activity, cells were incubated with Go6983 (ab144414, Abcam, $10 \mu \mathrm{M}$ ) for $2 \mathrm{~h}$.

\section{Immunofluorescence assay (IFA)}

hDPCs were inoculated in a 24-well plate and fixed with $4 \%$ polyformaldehyde (28906, Thermofisher) for 15 min. hDPCs were permeated for 30 min with $0.1 \%$ Triton X-100, cultured at ambient temperature for 15 min with $10 \%$ goat serum, and treated at $4^{\circ} \mathrm{C}$ with the primary antibody overnight. hDPCs were washed with PBS three times and incubated at ambient temperature for $1 \mathrm{~h}$ with the secondary Cy3-labeled antibody in dark conditions. Then, the cells were stained with 4',6-diamidino-2-phenylindole (D1306, Thermofisher) for $15 \mathrm{~min}$. Images were obtained at 400x magnification using a fluorescent microscope. 


\section{Subcellular fractionation}

Cells $\left(1 \times 10^{6}\right)$ were plated on 12 -cm dishes and grown for $36 \mathrm{~h}$. Then, the cells were harvested via scraping into $500 \mu \mathrm{L}$ of cell lysis buffer containing $10 \mathrm{mM} \mathrm{HEPES}(\mathrm{pH} 7.4), 10 \mathrm{mM} \mathrm{NaCl}, 1 \mathrm{mM} \mathrm{KH}_{2} \mathrm{PO}_{4}, 5$ $\mathrm{mM} \mathrm{NaHCO}_{3}, 1 \mathrm{mM} \mathrm{CaCl}_{2}, 0.5 \mathrm{mM} \mathrm{MgCl}_{2}$, and $5 \mathrm{mM}$ EDTA with complete protease inhibitor cocktail. Cells were allowed to swell for $5 \mathrm{~min}$, followed by Dounce homogenization for 50 -time strokes. The cells were then centrifuged at 5,000 rpm for 5 min, generating a pellet containing nuclei and debris and a supernatant of cytosol and plasma. Pellets were resuspended in $1 \mathrm{~mL}$ of buffer containing $10 \mathrm{mM}$ Tris (pH 7.5), $300 \mathrm{mM}$ sucrose, $1 \mathrm{mM}$ EDTA, and $0.1 \%$ NP40 with complete protease inhibitor cocktail and then pelleted, resuspended, and washed twice. The final pellets obtained were pure nuclei.

\section{Western blotting (WB)}

The cell lysis buffer was used for the lysis of hDPCs. Protein was determined using a bicinchoninic analysis kit, separated by $10 \%$ sodium dodecyl sulfate-polyacrylamide gel electrophoresis, and then transferred to a polyvinylidene fluoride or polyvinylidene difluoride membrane. Tween 20 was added to bovine serum albumin (BSA; 5\%) phosphate buffer to block nonbinding sites on the membrane for $1 \mathrm{~h}$. Protein was cultured at $4^{\circ} \mathrm{C}$ overnight with the primary antibody (p65, ab16502, Abcam, 1:1000; STAT3, ab5073, Abcam, 1:1000; PKC, ab19031, Abcam, 1:2500; PKA, ab187515, Abcam, 1:5000; TRPV1, PA1-748, Thermofisher, 1:1000; Phospho NF-kB p65 (S536), ab86299, Abcam, 1:500; Phospho STAT3 (S727), ab30647, Abcam, 1:500; Phospho PKC (T497), ab59411, Abcam, 1:1000; Phospho PKA alpha (Ser338), PA5-64489, Thermofisher, 1:500; Phospho TRPV1 (Ser503), PA5-64860, Thermofisher, 1:200; Actin, ab8227, Abcam, 1:5000; HSP70, ab2787, Abcam, 1:1000; Lamin B1, ab65986, Abcam, 1:1000), and the secondary antibody was bound to HRP (ab205718, ab205719, Abcam). The protein bands were stained, and the gray values were measured on a C-DiGit Blot Scanner.

\section{RNA extraction and quantitative real-time polymerase chain reaction (qPCR)}

Total RNA was extracted with glyceraldehyde 3-phosphate dehydrogenase (GAPDH) used as an internal standard. Next, under the following conditions, RNA was detected using qPCR (using an SYBR-Green Kit) in a $20-\mu \mathrm{L}$ system: predenaturation $\left(95^{\circ} \mathrm{C}, 10 \mathrm{~min}\right)$, denaturation $\left(95^{\circ} \mathrm{C}, 15 \mathrm{~s}, 40\right.$ cycles $)$, annealing $\left(60^{\circ} \mathrm{C}\right.$, $30 \mathrm{~s})$, and extension $\left(72^{\circ} \mathrm{C}, 30 \mathrm{~s}\right)$. Quantitative analysis was based on the $2^{-\triangle \Delta C T}$ method and normalized according to GAPDH. The sequences of primers used in this study was displayed as follows: IL-1 $1 \beta$ F: $5^{\prime}-$ CCA CAG ACC TTC CAG GAG AAT G-3', IL-1 $\beta$ R: 5'-GTG CAG TTC AGT GAT CGT ACA GG-3'; IL-6 F: 5'-AGA CAG CCA CTC ACC TCT TCA G-3', IL-6 R: 5'-TTC TGC CAG TGC CTC TTT GCT G-3'; TNF-a F: 5'-CTC TTC TGC CTG CTG CAC TTT G-3'; TNF-a R: 5'-ATG GGC TAC AGG CTT GTC ACT C-3'; PKA F: 5'-CAT ATT GCC GAA CAG ATT GG-3', PKA R: 5'-GCT GGA CTT CAT TGG CTG TA-3'; PKC F: 5'-CGA CTG TCT GTA GAA ATC TGG-3', PKC R: 5'-CAC CAT GGT GCA CTC CAC GTC-3'; STAT3 F: 5'-CTT TGA GAC CGA GGT GTA TCA CC3', STAT3 R: 5'-GGT CAG CAT GTT GTA CCA CAG G-3'; NF-kB F: 5'-GCA GCA CTA CTT CTT GA-3', NF-kB R: 5'-TCT GCT CCT GAG CAT TG-3'; TRPV1 F: 5'-CCA CAG CGG TGG TGA CGC-3', TRPV1 R: 5'-GGA GCT GTC 
CAG TGG A-3'.

\section{Enzyme-linked immunosorbent assay (ELISA)}

According to the manufacturer's instructions, the concentrations of interleukin (IL)-1 $\beta$ (BMS224-2, Thermofisher), IL-6 (EH2IL6, Thermofisher), TNF-a (KHC3011, Thermofisher), and CGRP (ABIN1095216, Antibodies-online) in the cell culture supernatants were analyzed using an ELISA kit. An automated microplate reader (SpectraMax $®$ M5) was used for the measurement of the optical density (OD) at 450 $\mathrm{nm}$. The concentrations of each sample were detected based on optical density and the concentration of the standard.

\section{Statistical analysis}

The results of our study are presented as means \pm standard deviations. Comparisons between two groups or multiple groups were analyzed using one-way ANOVA or a two-tailed Student's $t$-test, respectively. A P-value of $<0.05$ was considered to indicate a statistically significant difference.

\section{Declarations}

Ethics approval and consent to participate: All experiments were approved by the Ethics Committee of Rizhao People's Hospital. All subjects signed informed consent forms.

Consent for publication: Not applicable.

Availability of data and materials: The datasets used and/or analyzed during the current study are available from the corresponding author on reasonable request.

Competing interests: The authors declare that they have no competing interests.

Funding: No funding was received.

Authors' contributions: GL, GZ, and QX analyzed and interpreted the patient data regarding the hematological disease and the transplant. GL, GZ, MX, and XP performed the histological examination of the kidney. QX was a major contributor in writing the manuscript. All authors read and approved the final manuscript.

Acknowledgements: None.

\section{References}

1. Boyle M, Chun C, Strojny C, Narayanan R, Bartholomew A, Sundivakkam P, et al. Chronic inflammation and angiogenic signaling axis impairs differentiation of dental-pulp stem cells. PLoS One. 2014; 9: e113419. 
2. Lin J-J, Du Y, Cai W-K, Kuang R, Chang T, Zhang Z, et al. Toll-like receptor 4 signaling in neurons of trigeminal ganglion contributes to nociception induced by acute pulpitis in rats. Scientific reports. 2015; 5: 12549.

3. Serhan $\mathrm{C}$ N and Petasis N A. Resolvins and protectins in inflammation resolution. Chemical reviews. 2011; 111: 5922-43.

4. Renard E, Gaudin A, Bienvenu G, Amiaud J, Farges J, Cuturi M, et al. Immune cells and molecular networks in experimentally induced pulpitis. Journal of dental research. 2016; 95: 196-205.

5. Lee S-I, Min K-S, Bae W-J, Lee Y-M, Lee S-Y, Lee E-S, et al. Role of SIRT1 in heat stress-and lipopolysaccharide-induced immune and defense gene expression in human dental pulp cells. Journal of endodontics. 2011; 37: 1525-30.

6. Xiong $\mathrm{H}$, Wei $\mathrm{L}$ and Peng B. IL-17 stimulates the production of the inflammatory chemokines IL-6 and IL-8 in human dental pulp fibroblasts. International endodontic journal. 2015; 48: 505-11.

7. Zhao Y, Wang C-L, Li R-M, Hui T-Q, Su Y-Y, Yuan Q, et al. Wnt5a promotes inflammatory responses via nuclear factor KB (NF-KB) and mitogen-activated protein kinase (MAPK) pathways in human dental pulp cells. Journal of Biological Chemistry. 2014; 289: 21028-39.

8. Feng Z, Li Q, Meng R, Yi B and Xu Q. METTL 3 regulates alternative splicing of MyD88 upon the lipopolysaccharide-induced inflammatory response in human dental pulp cells. Journal of cellular and molecular medicine. 2018; 22: 2558-68.

9. Horst O V, Horst J A, Samudrala R and Dale B A. Caries induced cytokine network in the odontoblast layer of human teeth. BMC immunology. 2011; 12: 9.

10. Basbaum A I, Bautista D M, Scherrer G and Julius D. Cellular and molecular mechanisms of pain. Cell. 2009; 139: 267-84.

11. Rossato M F, Trevisan G, Walker C I B, Klafke J Z, de Oliveira A P, Villarinho J G, et al. Eriodictyol: a flavonoid antagonist of the TRPV1 receptor with antioxidant activity. Biochemical pharmacology. 2011; 81: 544-51.

12. Caterina M J, Schumacher M A, Tominaga M, Rosen T A, Levine J D and Julius D. The capsaicin receptor: a heat-activated ion channel in the pain pathway. Nature. 1997; 389: 816.

13. Cui J, Zhao H, Yi B, Zeng J, Lu K and Ma D. Dexmedetomidine attenuates bilirubin-induced lung alveolar epithelial cell death in vitro and in vivo. Critical care medicine. 2015; 43: e356.

14. Gertler R, Brown H C, Mitchell D H and Silvius E N. Dexmedetomidine: a novel sedative-analgesic agent. Baylor university Medical center proceedings. Taylor \& Francis. 2001; 14: 13-21.

15. Taniguchi T, Kidani Y, Kanakura H, Takemoto $Y$ and Yamamoto K. Effects of dexmedetomidine on mortality rate and inflammatory responses to endotoxin-induced shock in rats. Critical care medicine. 2004; 32: 1322-6.

16. Can M, Gul S, Bektas S, Hanci V and Acikgoz S. Effects of dexmedetomidine or methylprednisolone on inflammatory responses in spinal cord injury. Acta Anaesthesiologica Scandinavica. 2009; 53: 1068-72. 
17. Tasdogan M, Memis D, Sut N and Yuksel M. Results of a pilot study on the effects of propofol and dexmedetomidine on inflammatory responses and intraabdominal pressure in severe sepsis. Journal of clinical anesthesia. 2009; 21: 394-400.

18. Yang C-L, Tsai P-S and Huang C-J. Effects of dexmedetomidine on regulating pulmonary inflammation in a rat model of ventilator-induced lung injury. Acta Anaesthesiologica Taiwanica. 2008; 46: 151-9.

19. Nantel F, Denis D, Gordon R, Northey A, Cirino M, Metters K M, et al. Distribution and regulation of cyclooxygenase-2 in carrageenan-induced inflammation. British journal of pharmacology. 1999; 128 : 853-9.

20. Basu A, Das A S, Sharma M, Pathak M P, Chattopadhyay P, Biswas K, et al. STAT3 and NF-KB are common targets for kaempferol-mediated attenuation of COX-2 expression in IL-6-induced macrophages and carrageenan-induced mouse paw edema. Biochemistry and biophysics reports. 2017; 12: 54-61.

21. Yoshida A, Furube E, Mannari T, Takayama Y, Kittaka H, Tominaga M, et al. TRPV1 is crucial for proinflammatory STAT3 signaling and thermoregulation-associated pathways in the brain during inflammation. Scientific reports. 2016; 6: 1-11.

22. Chang J, Zhang C, Tani-Ishii N, Shi S and Wang C-Y. NF-KB activation in human dental pulp stem cells by TNF and LPS. Journal of dental research. 2005; 84: 994-8.

23. Takeda $\mathrm{K}$ and Akira S. STAT family of transcription factors in cytokine-mediated biological responses. Cytokine \& growth factor reviews. 2000; 11: 199-207.

24. Sukegawa S, Higuchi H, Inoue M, Nagatsuka H, Maeda S and Miyawaki T. Locally injected dexmedetomidine inhibits carrageenin-induced inflammatory responses in the injected region. anesthesia \& analgesia. 2014; 118: 473-80.

25. Walker S M, Howard R F, Keay K A and Fitzgerald M. Developmental age influences the effect of epidural dexmedetomidine on inflammatory hyperalgesia in rat pups. Anesthesiology: The Journal of the American Society of Anesthesiologists. 2005; 102: 1226-34.

26. Premkumar $L S$ and Ahern $G$ P. Induction of vanilloid receptor channel activity by protein kinase $C$. Nature. 2000; 408: 985.

27. Bhave G, Zhu W, Wang H, Brasier D, Oxford G S and Gereau IV R W. cAMP-dependent protein kinase regulates desensitization of the capsaicin receptor (VR1) by direct phosphorylation. Neuron. 2002; 35: 721-31.

28. Parolia A, Gee L S, Porto I and Mohan M. Role of cytokines, endotoxins (LPS), and lipoteichoic acid (LTA) in endodontic infection. J Dent Oral Disord Ther. 2014; 2: 1-5.

29. Elsalhy M, Azizieh F and Raghupathy R. Cytokines as diagnostic markers of pulpal inflammation. International endodontic journal. 2013; 46: 573-80.

30. Song F, Sun H, Wang Y, Yang H, Huang L, Fu D, et al. Pannexin3 inhibits TNF-a-induced inflammatory response by suppressing NF-KB signalling pathway in human dental pulp cells. Journal of cellular and molecular medicine. 2017; 21: 444-55. 
31. Zanini M, Meyer E and Simon S. Pulp inflammation diagnosis from clinical to inflammatory mediators: a systematic review. Journal of endodontics. 2017; 43: 1033-51.

32. Huang M-H, Wang B-S, Chiu C-S, Amagaya S, Hsieh W-T, Huang S-S, et al. Antioxidant, antinociceptive, and anti-inflammatory activities of Xanthii Fructus extract. Journal of Ethnopharmacology. 2011; 135: 545-52.

33. Molina $\mathrm{C}$ and Herrero J F. The influence of the time course of inflammation and spinalization on the antinociceptive activity of the a2-adrenoceptor agonist medetomidine. European journal of pharmacology. 2006; 532: 50-60.

34. Vinegar R, Schreiber W and Hugo R. Biphasic development of carrageenin edema in rats. Journal of pharmacology and experimental therapeutics. 1969; 166: 96-103.

35. Kathiria A S, Neumann W L, Rhees J, Hotchkiss E, Cheng Y, Genta R M, et al. Prohibitin attenuates colitis-associated tumorigenesis in mice by modulating p53 and STAT3 apoptotic responses. Cancer research. 2012; 72: 5778-89.

36. Timofeeva O A, Chasovskikh S, Lonskaya I, Tarasova N I, Khavrutskii L, Tarasov S G, et al. Mechanisms of unphosphorylated STAT3 transcription factor binding to DNA. Journal of Biological Chemistry. 2012; 287: 14192-200.

37. Nazıroglu M. TRPV1 channel: a potential drug target for treating epilepsy. Current neuropharmacology. 2015; 13: 239-47.

38. Moran M M, McAlexander M A, Bíró T and Szallasi A. Transient receptor potential channels as therapeutic targets. Nature reviews Drug discovery. 2011; 10: 601.

39. Rowbotham M C, Nothaft W, Duan W R, Wang Y, Faltynek C, McGaraughty S, et al. Oral and cutaneous thermosensory profile of selective TRPV1 inhibition by ABT-102 in a randomized healthy volunteer trial. Pain. 2011; 152: 1192-200.

40. Kissin I and Szallasi A. Therapeutic targeting of TRPV1 by resiniferatoxin, from preclinical studies to clinical trials. Current topics in medicinal chemistry. 2011; 11: 2159-70.

41. Miller F, Björnsson M, Svensson $O$ and Karlsten R. Experiences with an adaptive design for a dosefinding study in patients with osteoarthritis. Contemporary clinical trials. 2014; 37: 189-99.

42. Ma W and Quirion R. Inflammatory mediators modulating the transient receptor potential vanilloid 1 receptor: therapeutic targets to treat inflammatory and neuropathic pain. Expert opinion on therapeutic targets. 2007; 11: 307-20.

43. Gibbs J, Melnyk J and Basbaum A. Differential TRPV1 and TRPV2 channel expression in dental pulp. Journal of dental research. 2011; 90: 765-70.

44. Chung M-K, Lee J, Duraes $\mathrm{G}$ and Ro J. Lipopolysaccharide-induced pulpitis up-regulates TRPV1 in trigeminal ganglia. Journal of dental research. 2011; 90: 1103-7.

45. Kong W-L, Peng Y-Y and Peng B-W. Modulation of neuroinflammation: role and therapeutic potential of TRPV1 in the neuro-immune axis. Brain, behavior, and immunity. 2017; 64: 354-66. 
46. Huang $F$ M, Chang $Y$ C, Lee S S, Yang M L and Kuan Y H. Expression of pro-inflammatory cytokines and mediators induced by Bisphenol A via ERK-NFKB and JAK1/2-STAT3 pathways in macrophages. Environmental toxicology. 2019; 34: 486-94.

47. Xu K, Xiao J, Zheng K, Feng X, Zhang J, Song D, et al. MiR-21/STAT3 signal is involved in odontoblast differentiation of human dental pulp stem cells mediated by TNF-a. Cellular reprogramming. 2018; 20: 107-16.

48. He W, Qu T, Yu Q, Wang Z, Lv H, Zhang J, et al. LPS induces IL-8 expression through TLR 4, M y D 88, NF-kappa B and MAPK pathways in human dental pulp stem cells. International endodontic journal. 2013; 46: 128-36.

49. Lee J-C, Yu M-K, Lee R, Lee Y-H, Jeon J-G, Lee M-H, et al. Terrein reduces pulpal inflammation in human dental pulp cells. Journal of endodontics. 2008; 34: 433-7.

50. Nara K, Kawashima N, Noda S, Fujii M, Hashimoto K, Tazawa K, et al. Anti-inflammatory roles of microRNA 21 in lipopolysaccharide-stimulated human dental pulp cells. Journal of cellular physiology. 2019; 234: 21331-41.

51. Wang F, Han Y, Xi S and Lu Y. Catechins reduce inflammation in lipopolysaccharide-stimulated dental pulp cells by inhibiting activation of the NF-KB pathway. Oral Diseases. 2020;

52. Jing L, Rong-yin T and Yan L. Study of primary culture method of human pulp cell [J]. Chinese Journal of Conservative Dentistry. 2006; 6:

\section{Figures}

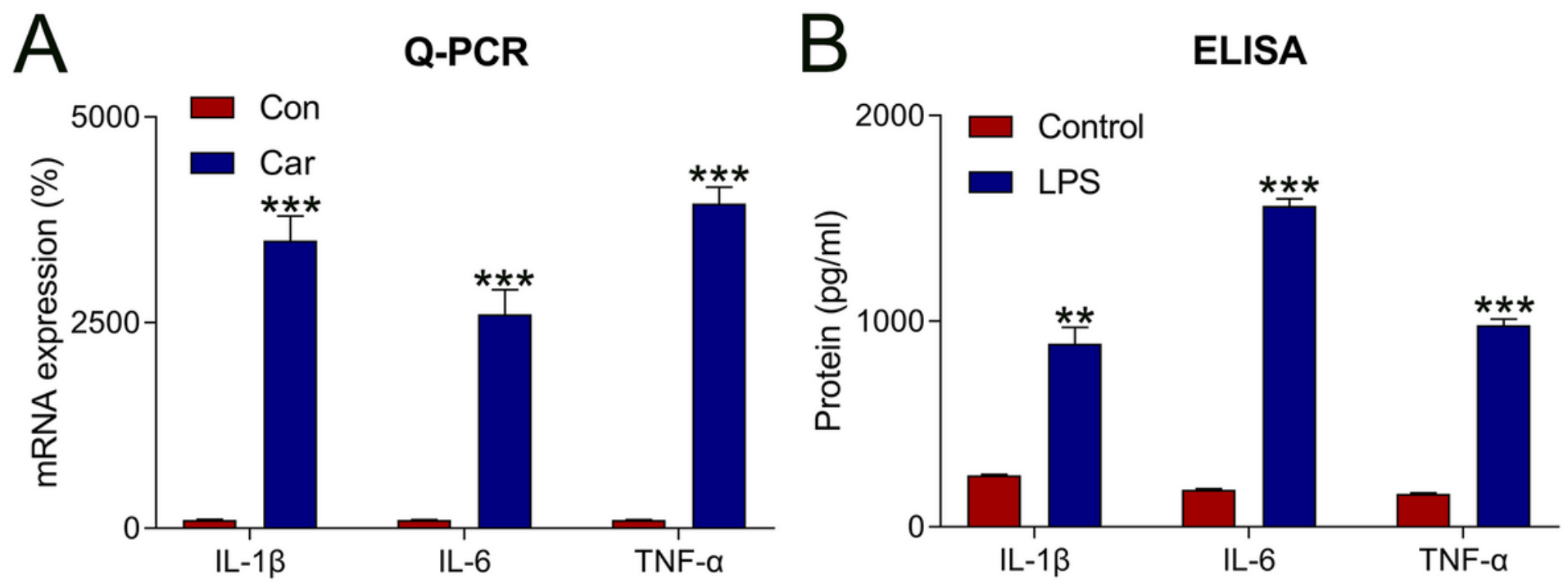

\section{Figure 1}

Car-triggered inflammation in hDPCs. hDPCs were treated with either $10 \mu \mathrm{M}$ Car or PBS (as control) for 2 h. After lysis, the expressions of IL-1 $\beta$, IL-6, and TNF-a were assessed by (A) qPCR and (B) ELISA. Data are 
expressed as means \pm standard deviations. Comparisons between two groups were analyzed by t-test. **P $<0.01, * * * P<0.001$.
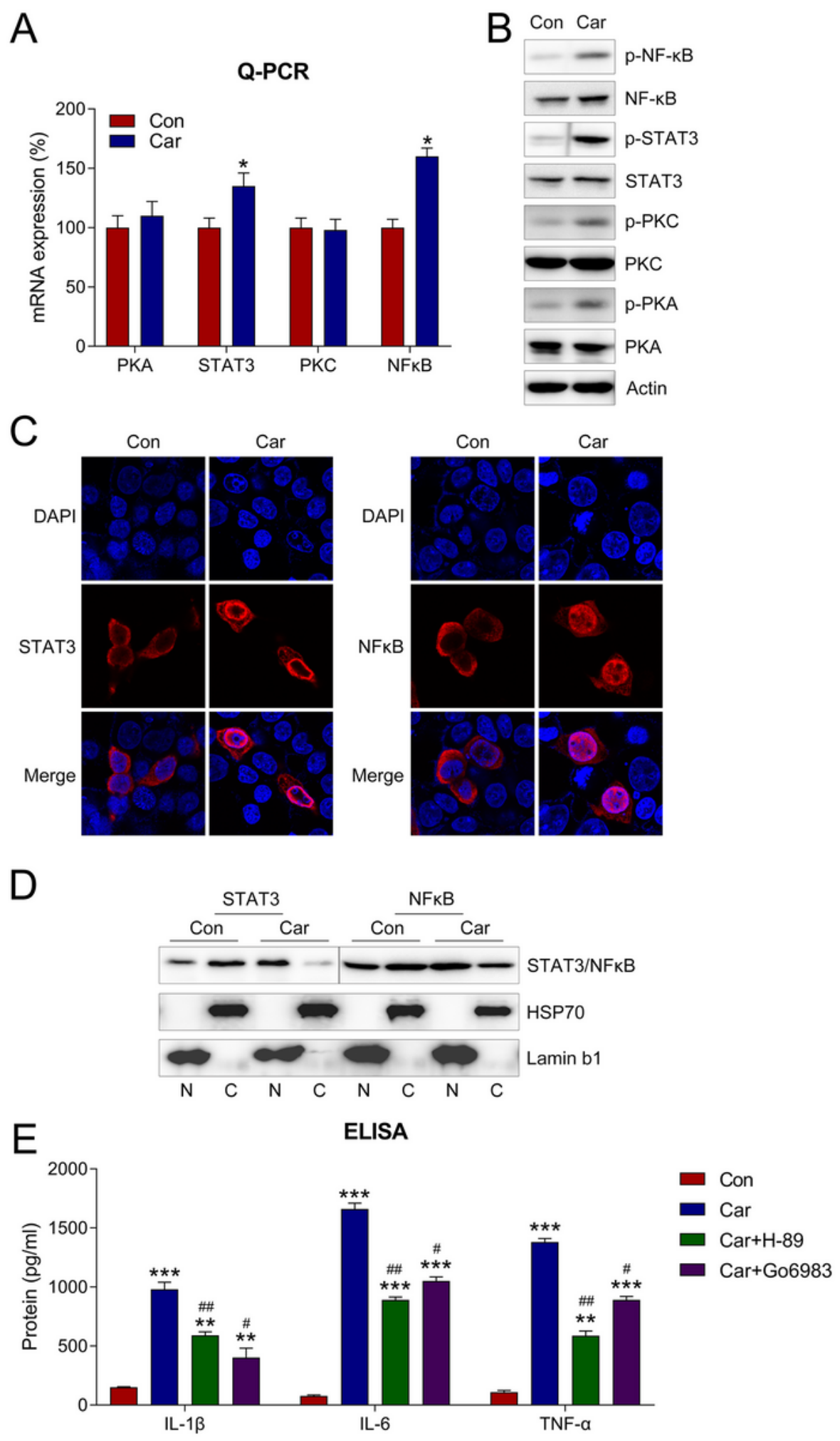

Figure 2

Car activated both PKA-STAT3 and PKC-NF-KB signaling in hDPCs. (A) Cell lysates were subjected to qPCR to assess the expressions of PKA, PKC, STAT3, and NF-KB. (B) WB was performed to probe with antibodies for phosphorylation and expression PKA, PKC, STAT3, and NF-kB in cell lysates. (C) IFA 
detected the cellular location of STAT3 and NF-KB in hDPCs. (D) Cell fractionation assay showed the location of STAT3 and NF-KB in nuclear and cytoplasmic fractions of hDPCs. (E) hDPCs were co-treated with either $100 \mu \mathrm{M}$ Car and $10 \mu \mathrm{M} \mathrm{H}-89 /$ Go6983 for $2 \mathrm{~h}$. The expressions of IL-1 $\beta$, IL-6, and TNF-a were assessed by ELISA. Data are expressed as means \pm standard deviations. Comparisons between two groups were analyzed by t-test. ${ }^{*} \mathrm{P}<0.05,{ }^{\star *} \mathrm{P}<0.01,{ }^{\star \star *} \mathrm{P}<0.001$ vs. Control group; $\# \mathrm{P}<0.05, \# \# \mathrm{P}<0.01$ vs. Car group.

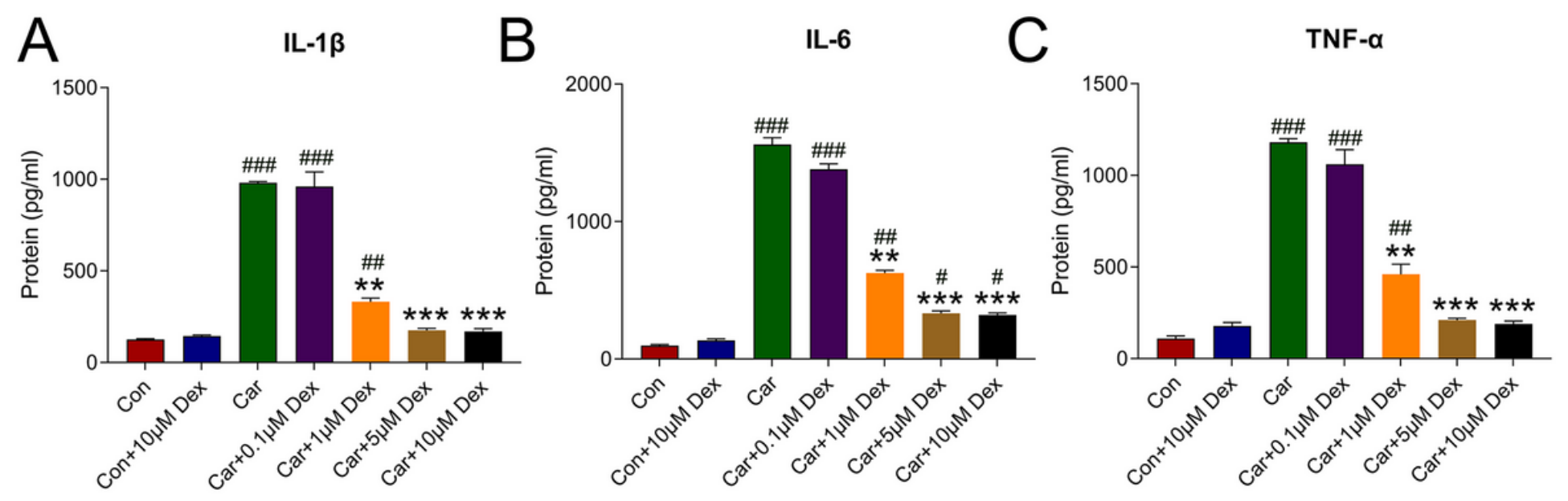

\section{Figure 3}

Dex ameliorated the generation of proinflammatory cytokines in hDPCs. hDPCs were co-treated with Car or different concentrations of Dex $(0,0.1,1,5$, or $10 \mu \mathrm{M})$ for $2 \mathrm{~h}$. The expressions of IL-1 $13(\mathrm{~A})$, IL-6 (B), and TNF- $\mathrm{a}(\mathrm{C})$ at $2 \mathrm{~h}$ after Car and Dex treatment were detected by ELISA. Data are expressed as means \pm standard deviations. Comparisons between multiple groups were analyzed by one way ANOVA. ${ }^{*} \mathrm{P}<$ $0.01,{ }^{* *} \mathrm{P}<0.001$ vs. Car group; \#\#P<0.01, $* \star * \mathrm{P}<0.001$ vs. Control group.
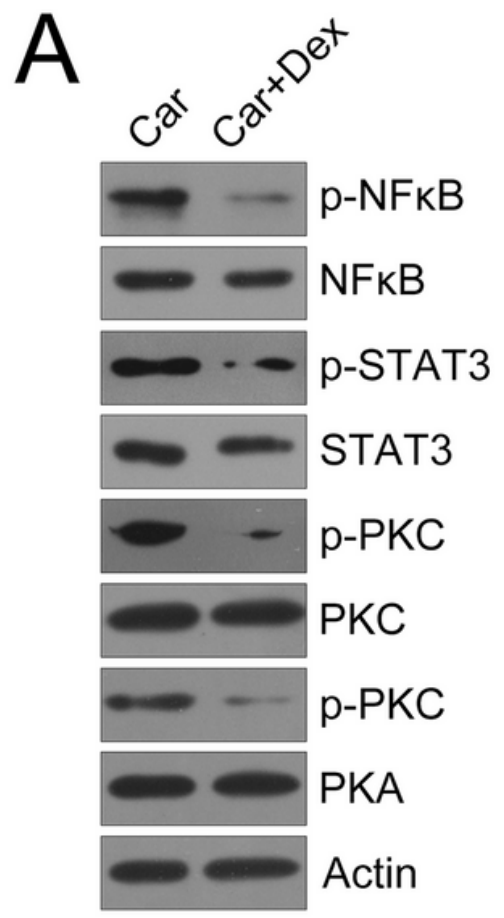
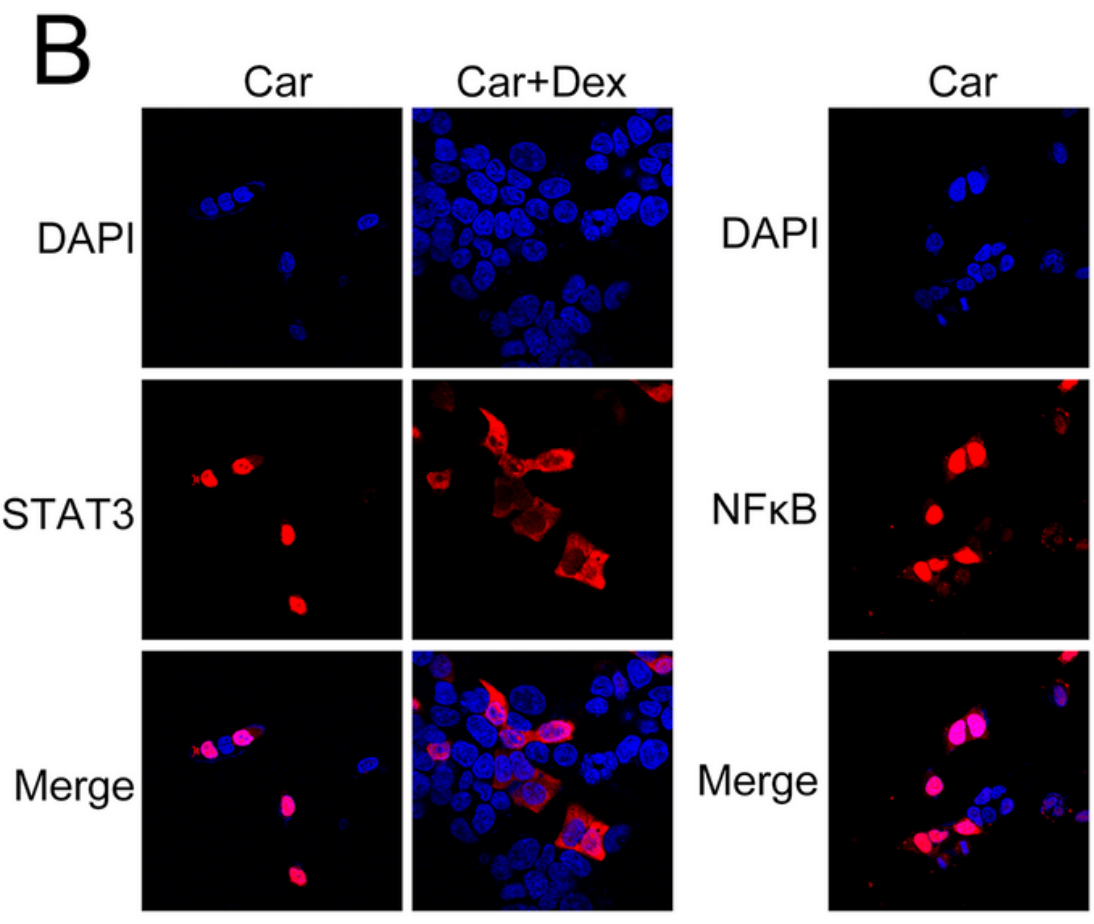
Figure 4

Dex deactivated both PKA-STAT3 and PKC-NF-KB signaling in hDPCs. hDPCs were cotreated with Car $(100 \mu \mathrm{M})$ or Dex $(5 \mu \mathrm{M})$ for $2 \mathrm{~h}$. (A) WB was performed to probe with antibodies for the phosphorylation and expression of PKA, PKC, STAT3, and NF-KB in cell lysates. (B) IFA detected the cellular location of STAT3 and NF-KB in hDPCs.

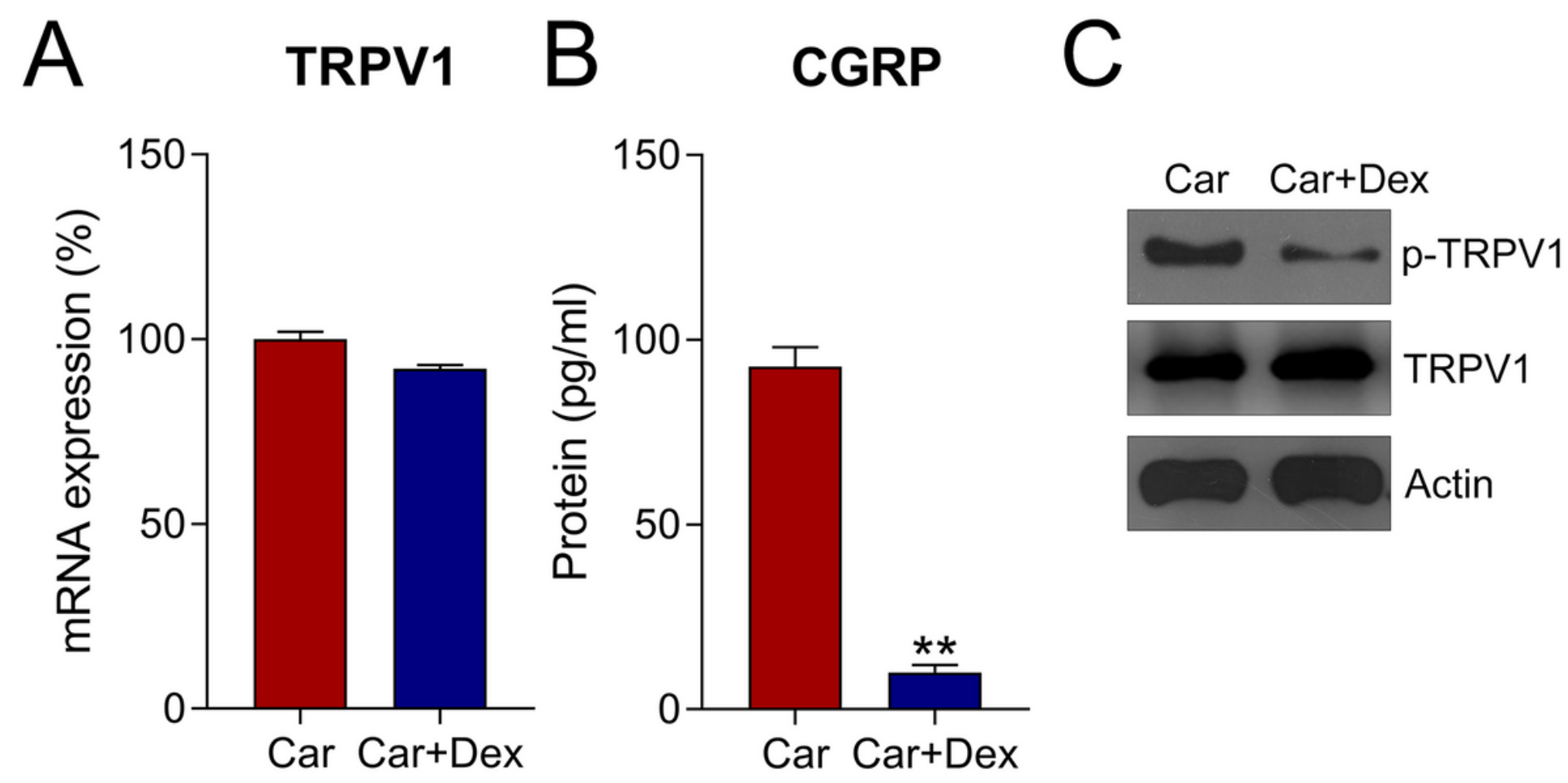

Figure 5

Dex desensitized the TRPV1 channel in hDPCs. (A) qPCR revealed the expression of TRPV1 in hDPCs. (B) The release of CGRP in cell culture medium was determined at $2 \mathrm{~h}$ after Car and/or Dex cotreatment by ELISA. (C) WB analyses determined the expression and phosphorylation of TRPV1 in hDPCs. Data are expressed as means \pm standard deviations. Comparisons between two groups were analyzed by $\mathrm{t}$-test. $\star * \mathrm{P}<0.01$. 


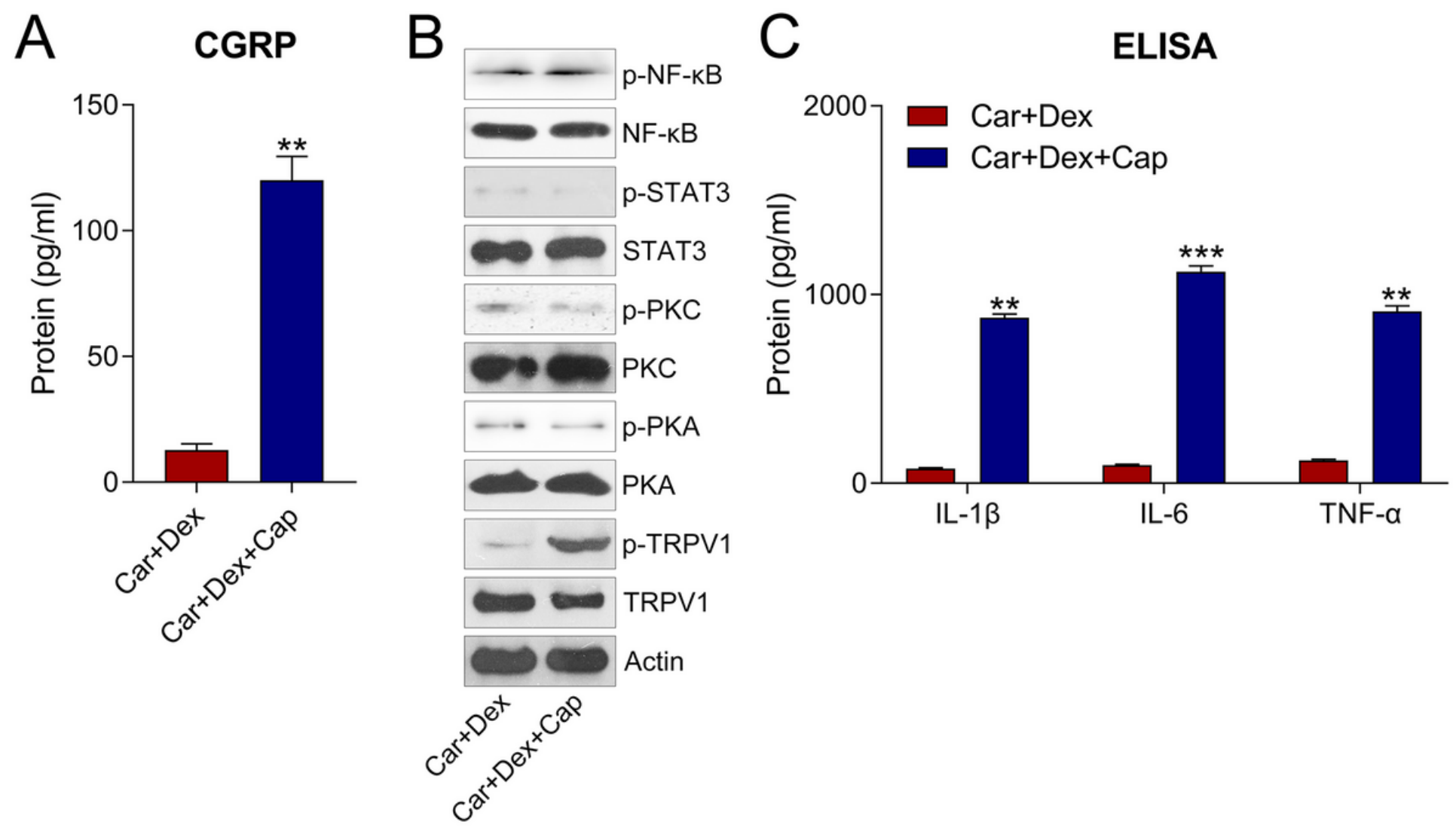

Figure 6

Cap treatment restored Car-induced inflammation in hDPCs. hDPCs were cotreated with Car $(100 \mu \mathrm{M})$, Dex $(5 \mu \mathrm{M})$, and/or Cap $(5 \mu \mathrm{M})$ for $2 \mathrm{~h}$. (A) The release of CGRP in cell culture medium was determined at $2 \mathrm{~h}$ after Car and/or Dex cotreatment by ELISA. (B) WB analyses were used to examine the phosphorylation and expression of PKA, PKC, STAT3, NF-KB, and TRPV1 in cell lysates. (C) ELISA was conducted to assess IL-1 $\beta$, IL- 6 , and TNF- $\alpha$ expression. Data are expressed as means \pm standard deviations. Comparisons between two groups were analyzed by t-test. $* * P<0.01, * \star * P<0.001$. 